\title{
Gênero e ensino de Artes Visuais: desafios, armadilhas e resistências
}

\author{
Taís Ritter Dias ${ }^{1,2}$ (iD 0000-0003-3758-5551 \\ Luciana Gruppelli Loponte ${ }^{3}$ (DD) 0000-0002-0552-0529 \\ 'Universidade Federal do Rio Grande do Sul, Porto Alegre, RS, Brasil. 90046-900 - \\ ppgedu@ufrgs.br \\ ${ }^{2}$ Escola Estadual de Ensino Médio Patrulhense, Santo Antônio da Patrulha, RS, Brasil. \\ 95500-000 - escolapatrulhense@yahoo.com.br/coordenacaopatrulhense@gmail.com \\ ${ }^{3}$ Universidade Federal do Rio Grande do Sul, Faculdade de Educação, Departamento \\ de Ensino e Currículo, Porto Alegre, RS, Brasil. 90046-900 - dec@ufrgs.br
}

\section{$-$}

Resumo: Este artigo origina-se de uma inquietação suscitada pela ausência de pesquisas acadêmicas que articulem estudos de gênero e ensino de Artes Visuais. Para friccionar e problematizar o silêncio que ronda este tema, realizamos três movimentos. Iniciamos contextualizando alguns impasses que reiteradamente têm afastado a discussão de gênero da disciplina; em seguida, realizamos a análise de alguns artigos - disponíveis nos anais de dois importantes eventos da área de arte e educação que abordam a temática. Nessa análise, lançamos mão dos conceitos gênero, poder e resistência, apreendidos de autores e autoras vinculados ao pós-estruturalismo, visando ao apontamento de alguns desafios colocados por esses artigos. No último movimento, esboçamos algumas intervenções feministas, ensejando que tais discussões se proliferem no ensino de arte.

Palavras-chove: estudos de gênero; ensino de artes visuais; feminismos.

Gender and Art Education: Challenges, Pitfalls, Resistances

Abstract: This paper originates from a concern raised by the lack of academic research articulating gender studies and art education. To rub and problematize the silence that surround this theme, we made three movements. We begin by contextualizing some impasses that have repeatedly removed the gender discussion of Art, as a school discipline; next, we analyze some papers - available in the annals of two important events in the area of art and education - that deal with the theme; in this analysis, we use the concepts of gender, power and resistance, seized from authors linked to poststructuralism, aiming to point out some of the challenges posed by these papers. In the last movement, we outline some feminist interventions, allowing such discussions to proliferate in the teaching of art.

Keywords: Gender studies; Art education; Feminism.

\section{Introdução}

No presente artigo visamos à discussão das ressonâncias dos estudos de gênero no ensino

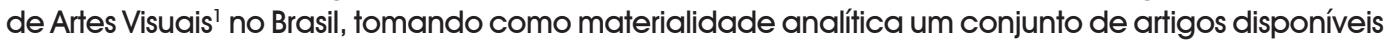
nos anais de dois eventos nacionais: o CONFAEB (Congresso Nacional da Federação de ArteEducadores do Brasil) e os Encontros Nacionais da ANPAP (Associação Nacional de Pesquisadores

\footnotetext{
1 O foco da discussão apresentada é o ensino de Artes Visuais, porém, muitas das problematizações aqui presentes podem ser pensadas para o ensino de outras linguagens artísticas, como a música, o teatro, a dança, o cinema ou a literatura. Na maior parte do texto, optamos pela expressão "ensino de Artes Visuais". No entanto, quando nos referimos à discussão mais geral sobre a área usamos "ensino de Arte" ou "componente curricular Arte", que é o modo como esse componente é nomeado nos documentos curriculares oficiais, referindo-se ao ensino de Artes Visuais, Música, Teatro ou Dança.
} 
em Artes Plásticas). A necessidade de realizar este balanço adveio da constatação de uma carência nas publicações que se debruçam sobre o tema. Murmúrios sobre o mutismo da articulação gênero e ensino de Artes Visuais nas pesquisas brasileiras vêm se avolumando nos apontamentos realizados pelos/as poucos/as autores/as que a ela têm se dedicado (Luciana Gruppelli LOPONTE, 2015; Belidson DIAS, 2011 ; Andréa Senra COUTINHO, 2009; Taís Ritter DIAS, 2017). ${ }^{2}$ Em face desse aparente uníssono, isto é, do consenso de que há uma carência de pesquisas sobre o tema, interrogamo-nos sobre a possibilidade de ir além de uma afirmação reiterativa sobre um estado de invisibilidade, um diagnóstico que se repete indefinidamente. Assim, perguntamo-nos em que medida poder-se-ia contribuir para superar a propalada ausência da perspectiva de gênero no ensino de Artes Visuais?

Por certo, pesquisas que buscam identificar a incipiência desse debate concitam e pavimentam avanços. Por outro lado, podem gerar uma sensação de estagnação e impotência. Há que se pensar em que medida fixar a ausência como uma condição que colabora para que determinadas práticas permaneçam recônditas e submersas. Em meio a esses ruídos e incômodos, desponta a relevância de avaliar o que, efetivamente, tem sido feito por pesquisadores/as e professores/ as em diferentes contextos, ainda que os documentos escolhidos para a análise sejam um pequeno estrato da pesquisa acadêmica no Brasil. Pensamos ser importante deslindar como têm abordado a temática, quais estratégias sugerem e, sobretudo, o que podemos aprender com eles/elas, tornando possível elaborar outros relevos e políticas de atuação no ensino de Artes Visuais.

\section{Obstáculos a uma articulação possível}

Para tratar da interface de que nos ocupamos neste artigo, qual seja, gênero e ensino de Artes Visuais, é de fulcral relevância levar em conta o contexto em que se inscreve o componente curricular Arte e, em especial, o fato de que tem se esquivado dele as questões de gênero. Assim, intentamos trazer à tona alguns obstáculos que impedem essa interface. Tais obstáculos, antes de serem uma pecha da área do ensino de Artes Visuais ou mesmo dos/das profissionais nela inseridos/ as, pertencem a uma densa tessitura histórica e política que empurra as questões de gênero para um horizonte distante do campo de atuação docente.

Iniciamos lembrando que, se, sistematicamente, as discussões de gênero são alvo de frequentes ameaças no currículo escolar, ${ }^{3}$ algo não muito diferente ocorre com o ensino de Arte. A sinalização de uma possível retirada do componente curricular Arte do Ensino Médio, como a que se anunciou com a Medida Provisória 746, ${ }^{4}$ em 2016 (BRASIL, 2017), é uma constante na sua história. Foi apenas em 1996, com a promulgação da LDB 9394 (BRASIL, 1996), e após mobilizações de diversas entidades representativas, que a disciplina se tornou obrigatória em todos os níveis da educação básica. Dessa indefinição em torno da presença da Arte na escola resultam muitas batalhas políticas, teóricas e epistemológicas sobre as nomenclaturas mais adequadas à disciplina, sobre os conteúdos e as abordagens mais relevantes, sobre os argumentos mais legítimos para assegurar sua permanência no currículo. São disputas de afirmação da área, importantes e necessárias, mas que, por seu turno, acabam distanciando-a de outras urgências políticas da educação, como, por exemplo, as questões de gênero, sexualidade, raça, etnia, entre outras.

O lastro políico instável quanto à permanência da Arte e do debate de gênero na escola apenas parece solidificar a rarefação de interlocuções entre esses campos. Afinal, se o ensino de Artes Visuais carece de argumentos - ao menos aos olhos daqueles que legislam sobre educação no Brasil - para a sua afirmação no cenário educacional, como se aliar a uma temática tão polêmica e, atualmente, perseguida como têm sido as questões de gênero? O desejo de afirmação da área não seria um motivo a mais para que se deixe de lado um tema de recepção tão incerta nesses tempos?

Todas essas tensões refletem-se nos exíguos empreendimentos que contemplam as relações de gênero nos cursos de Licenciatura em Artes Visuais. A insuficiência desse debate na graduação

\footnotetext{
${ }^{2}$ Além desses/as autores/as, Ana Mae Barbosa (2005), reconhecidamente uma das pesquisadoras pilares da área de arte e educação no Brasil, vem chamando a atenção à falta de pesquisas que tratem do tema (BARBOSA, Ana Mae. "Pesquisa em Arte/Educação: recorte sócio-político". Educação e Realidade, Porto Alegre, v. 30, n. 2, p. 291- 301, jul./ dez. 2005). Em levantamentos mais recentes, como os empreendidos por Loponte (2015) e Edvandro Luise Sombrio de SOUZA (2017), identifica-se a persistência de um cenário pouco aberto às questões políticas e, especialmente, às discussões de gênero.

${ }^{3}$ Vide as recentes movimentações políticas que ambicionam solapar as questões de gênero da escola, entre elas, 0 discurso que combate a chamada "ideologia de gênero" que tem se espraiado por diversas instâncias legislativas e sociais, além do Projeto de Lei Escola Sem Partido, que tem como uma de suas frentes a eliminação da discussão de gênero e sexualidade da escola. O movimento de elisão de gênero da educação pôde ser testemunhado, além disso, na elaboração da Base Nacional Curricular Comum - de cuja redação final foram retiradas as expressões "identidade de gênero" e "orientação sexual" - somando-se aquele empreendido em 2014 à época da construção do Plano Nacional de Educação e, posteriormente, em 2015, nos Planos Estaduais e Municipais.

${ }^{4}$ A Medida Provisória 746 estabeleceu a reforma do Ensino Médio alterando a LDB (Lei 9.394/1996). Na primeira versão de seu texto, a medida propôs a retirada da disciplina Arte do Ensino Médio. Contudo, a partir de inúmeras reivindicações, houve um recuo nessa decisão. Esta medida provisória originou a Lei 13415, de 17/02/2017 (BRASIL, 2017), que altera a LDB.
} 
é vastamente mencionada em relatos de formação docente e em estudos de pesquisadores/as da área (Luciano Parreira BUCHMANN; Mariana Galli FIGUEIREDO, 2014; Isabela FRADE; Alessandra CAETANO; Jéssica GÓES; Letícia SARAIVA, 2012).

No que tange à formação, há que se considerar ainda a existência de um enorme descompasso entre o número de professores/as com habilitação específica em Artes Visuais e a demanda das escolas, como é indicado por recentes levantamentos. ${ }^{5}$ Aponta-se que um número muito reduzido dos/as docentes que leciona a disciplina possui licenciatura na área, isto é, na maioria das vezes são professores/as de formações diversas que ensinam Arte na escola.

O fato de que durante o seu percurso escolar os/as alunos/as não tenham contato com o/a professor/a da área indubitavelmente sedimenta determinadas noções de arte do domínio do senso comum: arte como dom divino; como representação de certas noções de beleza; ${ }^{\circ}$ como expressão da loucura; como fazer manual e ornamental, desprovido da dimensão intelectual. Esses entendimentos sobre a arte e sobre o papel que a ela cabe na escola, evidentemente, não permitem vislumbrar as relações de gênero como algo possível de ser explorado pelos/as professores/ as. Todavia, afora essas noções do público leigo, por assim dizer, existem outras concepções compartilhadas entre os/as profissionais da área que não dão margem às infiltrações de gênero.

O formalismo7 é, com frequência, referido como um dos arcabouços teórico-metodológicos que interdita, tacitamente, discussões políticas e de gênero no ensino de Artes Visuais (LOPONTE, 2008; COUTINHO, 2009; DIAS, 2011 ; SOUZA, 201 7; EFLAND; FREEDMAN; Patrícia STUHR, 2003). Trata-se de uma acepção que, assentada na prerrogativa da autonomia, toma a arte como manifestação puramente visual e isolada da sua dimensão social e histórica, resultando em análises e leituras que elevam a Arte a um território incólume a qualquer questão política. Conjugando-se o formalismo com as consagradas narrativas lineares e evolucionistas da história, naturaliza-se, consequentemente, a ausência das mulheres artistas e conserva-se a figura do artista masculino, gênio, original, individual. Logo, essa forma de abordar o objeto artístico endossa uma visão hierárquica, ensimesmada e excludente das Artes Visuais na escola.

É no limiar dessas discussões que argumentamos que a perspectiva de gênero no ensino de Artes Visuais não se limita à inclusão de obras de artistas mulheres. Sabe-se que uma demanda recorrente da discussão feminista e de gênero na arena das Artes Visuais tem sido a denúncia do apagamento das mulheres artistas nos grandes relatos da história da arte. ${ }^{8}$ Esta parece ser uma demanda longe de ser dirimida se levarmos em conta a presença assimétrica de gênero, particularmente desfavorável às artistas mulheres, verificada nos livros e materiais didáticos (COUTINHO, 2009), nos cursos de formação docente (BUCHMANN, FIGUEIREDO, 2014; FRADE; CAETANO; GÓES; SARAIVA 2012), e, em última instância, nos currículos e planejamentos dos professores da área.

Entretanto, é preciso admitir que somente a adição de artistas mulheres nas aulas de Artes Visuais não implica, necessariamente, uma abordagem política da arte ou uma leitura que tenha como panorama as discussões de gênero, podendo, inclusive, restituir e fortalecer análises estritamente formalistas. Além disso, tal inserção pode se tornar uma estratégia puramente reformatória, um conteúdo programático a mais que os/as professores/as sentem-se obrigados/as a cumprir: "se nunca falamos de mulheres artistas, basta que destinemos um dia do ano para homenageá-las (o Dia da Mulher, por exemplo)". Enfim, um acréscimo que pode se encaixar de muitos modos com o que já está consagrado no ensino de Artes Visuais, sem alterar concepções de gênero hegemônicas, discriminações correntes e efeitos de poder que aí circulam.

\footnotetext{
${ }^{5}$ Dos/das docentes que atuam no Ensino Médio, $85,1 \%$ não possuem habilitação específica em Artes (TINOCO, Dandara. "Falta de licenciatura atinge $35 \%$ de professores do nível fundamental". O Globo, Rio de Janeiro, 07/06/ 2014. Disponível em http://oglobo.globo.com/sociedade/educacao/falta-de-licenciatura-atinge-35-de-professoresdo-nivel-fundamental-12402843. Acesso em 15/05/2016).

${ }^{\circ}$ A atual irrupção de práticas de censura das Artes Visuais, como a que ocorreu com o fechamento da exposição Queermuseu, sediada pelo Santander Cultural (Porto Alegre-RS), e os protestos contra a performance La Bête do artista carioca Wagner Schwartz realizada no Museu de Arte Moderna (São Paulo-SP), permitiram entrever as concepções de arte difundidas no senso comum. As ideias de que a arte é algo sublime e a manifestação, por excelência, do belo, foram amplamente utilizadas a fim de argumentar que estas produções artísticas não se enquadram no estatuto da arte.

${ }^{7}$ Convém assinalar que preferimos utilizar o termo "formalismo" ou "abordagem formalista", em detrimento de outras expressões como "arte moderna", pois pensamos que seja importante ter o cuidado com possíveis generalizações que tais termos e expressões carregam. Afirmar que a arte moderna, em sua totalidade, é formalista, implica uma homogeneização e uma exclusão de outras formas de pensar e fazer arte que coexistiram nesse período histórico (STEINBERG, Leo. "Outros Critérios". In: FERREIRA, Glória; MELLO, Cecília Cotrim de (Orgs.). Clement Greenberg e o debate crítico. Rio de Janeiro: Jorge Zahar, 1997. p. 175-210; EFLAND, Arthur. "Cultura, sociedade, arte e educação num mundo pós-moderno". In: BARBOSA, Ana Mae; GUINSBURG, Jacob (Orgs.). O Pós-Modernismo. São Paulo: Perspectiva, 2005. p. 173-188).

8 É possível apontar o célebre artigo "Why have there been no great women artists?", de Linda Nochlin (1989), publicado originalmente em 1971 pela revista Art News - como aquele que inaugurou esse processo de denúncia em torno do silenciamento das mulheres como criadoras na história da arte. O artigo disparou uma série de estudos que objetivou recuperar a história da ausência das mulheres, trazendo à luz trabalhos de artistas desde os tempos mais longínquos (NOCHLIN, Linda. "Why have there been no great women artists?". In: NOCHLIN, Linda. Women, art and power and other essays. Colorado: Westview, 1989. p. 145-175).
} 
Ao inferir a importância da perspectiva de gênero, por muitos ainda considerada estrangeira ao domínio da arte, assumimos o pressuposto de que as imagens são práticas discursivas que veiculam valores de uma época, interpelam-nos a determinados gestos e condutas, representam sujeitos e identidades de gênero. Podem ser entendidas como um "texto discursivo" que instaura certas formas de "ver e dizer a realidade" (Maria Simone Vione SCHWENGBER, 2012, p. 265). Ademais, as diversas práticas que se inscrevem no campo artístico (artísticas, curatoriais, críticas, museais, documentais etc.) integram a dinâmica social e, logo, estão mergulhadas nas relações de poder e nos regimes de verdade de um dado momento histórico. Portanto, "há mais na superfície das imagens para analisar do que supõem as leituras de imagem formalistas mais comuns" (LOPONTE, 2008, p. 155).

Como expomos até aqui, a lista de impasses em torno da intersecção gênero e ensino de Artes Visuais é ampla e, certamente, poderia ser estendida, se houvesse um fôlego maior para fazê-la. Há uma série de tensões e nervuras políticas em torno do debate de gênero que, amalgamadas com o lugar ocupado pela arte na escola, podem gerar a sensação de que tal tema é intransitável. Entretanto, é preciso ter em vista esses desafios não para gerar uma paralisia ou um embotamento, mas para fomentar a criação de ações de enfrentamento. Justamente para assinalar o quão possível pode ser o cruzamento gênero e ensino de Artes Visuais, apresentamos, na sequência, alguns artigos que se curvam sobre o tema. A existência destes artigos abre uma fenda política profícua e inspiradora nos indicando que antes de se caracterizar por um profundo silêncio, a articulação gênero e ensino de Artes Visuais é marcada por práticas de resistência corajosas, ainda que, por vezes, solitárias e dispersas.

\section{Usos do concelto gênero em eventos de Artes Visuais}

Como parte do estudo levado a cabo, analisamos alguns dos usos do conceito de gênero adotados por autores/as que circularam no CONFAEB $^{9}$ e nos Encontros Nacionais da ANPAP ${ }^{10}$, no período entre 2007 e 2015. Para a triagem dos artigos foram consultados os sites dos eventos e os anais disponíveis online, de onde pinçamos aqueles que propunham articulações entre educação, gênero e arte, seja em seus títulos e/ou nas palavras-chave.

Merece destaque a explicitação das escolhas referentes ao modo de operar com os artigos selecionados. Estas escolhas foram orientadas pelo conceito gênero - que tomamos como um conceito teórico e metodológico - pautado por autoras filiadas à vertente pós-estruturalista (Joan SCOIT, 1995; Guacira Lopes LOURO, 2003; Judith BUTLER, 2016; Beatriz PRECIADO, 2011). Nessa perspectiva, compreende-se que as subjetividades de gênero não se explicam por uma essência pré-existente e imutável, tampouco por uma definição meramente biológica. Trata-se de um conceito que lida com a provisoriedade das posições de sujeito e dos discursos que nos enredam, movendose num constante fazer[-se] e desfazer[-se]. Seguindo essa linha, desembaraçar-se de concepções fundacionais de sujeito e de gênero, dos binarismos e das normalizações que atravessam nossas existências tem sido o corolário primeiro estabelecido pelas autoras com as quais dialogamos aqui.

Afora o conceito gênero, recorremos aos conceitos poder/resistência tomando como norte teórico o pensamento de Michel FOUCAULT (2014), bem como as interlocuções de comentadores de sua obra (Didier ERIBON, 1990; Hubert DREYFUS; Paul RABINOW, 1995). Isto porque, no solo teórico em que nos colocamos, compreendemos que as subjetividades de gênero são constituídas por certos efeitos de poder e por práticas de resistência. Ademais, partimos do pressuposto de que as produções textuais analisadas constituem-se, num certo sentido, como práticas de resistência, na medida em que buscam enfrentar processos de desigualdade, discriminação e silenciamento de gênero observados no contexto escolar. Assim, o que buscamos examinar nos estudos foi, precisamente, como as abordagens de gênero propostas pelos/as seus/suas autores/as desestabilizam, reformam ou reforçam determinados efeitos de poder. Tendo em vista este panorama teórico-metodológico, bem como o território movente da arte na educação, é que tecemos as análises dos artigos selecionados.

No que concerne ao manuseio desses artigos, sinalizamos que, após a fase de rastreamento, que perfez um montante de 44 artigos, procedemos a uma leitura de sondagem, procurando destacar as principais recorrências. Devido aos diferentes enfoques e direcionamentos propostos pelos/as autores/as, criamos quatro eixos de análise: a) pesquisas voltadas para a história da arte ou para a produção poética do/a autor/a do estudo; b) pesquisas com ênfase na formação docente e outros temas correlatos à figura do/a professor/a; c) pesquisas que tratam de experiências pedagógicas/artísticas com populações não escolares; d) pesquisas voltadas ao ensino de Artes Visuais em escolas. Para o presente texto, optamos por efetuar um recorte da análise desses eixos,

${ }^{9}$ O CONFAEB (Congresso Nacional da Federação de Arte-Educadores do Brasil) é um evento anual que se ocupa do ensino de artes, abarcando seus diferentes segmentos: teatro, dança, música e artes visuais.

10 O Encontro Nacional da ANPAP (Associação Nacional de Pesquisadores em Artes Plásticas) trata-se de um evento anual voltado exclusivamente às artes visuais que engloba diferentes áreas de atuação do campo artístico: História, Teoria e Crítica de Arte; Educação em Artes Visuais; Poéticas Artísticas; Curadoria; Patrimônio, restauração. 
devido ao escopo reduzido de que dispomos. Desse modo, focamos no quarto eixo, isto é, aquele referente ao ensino de Artes Visuais na escola. Deste eixo, por sua vez, nos concentramos mais detidamente em duas abordagens que julgamos suscitarem questões nevrálgicas para o debate. Dividimos as seções subsequentes, portanto, de modo a descrever e tensionar essas duas abordagens, sendo que, na primeira delas, apresentamos apenas três artigos e, na segunda, apenas um artigo, uma vez que visamos ao aprofundamento dos aspectos frisados na análise.

\section{Palavras sujas}

Os artigos incluídos nessa abordagem caracterizam-se por flertar com o senso comum, recorrendo a estratégias que, em última análise, podem autenticar discursos que essencializam determinados sujeitos. Ao tratar de senso comum, referimo-nos a ideias e discursos fartamente compartilhados entre sujeitos que ocupam variadas posições na extensão social, o que demarca uma "circulação generalizada" (Céli Regina Jardim PINTO, 1989, p. 44). Definindo o discurso do senso comum, Pinto (1989) descreve-o como a "bagagem discursiva de um povo", assinalando o grande potencial de captura que possui em virtude de sua maleabilidade e "capacidade de perder seus laços com o discurso original" (PINTO, 1989, p. 44) quando incorporado a novas demandas políticas e culturais.

Ao indicar que algumas abordagens carregam discursos do senso comum, não queremos afirmar, todavia, que não possuam referências teóricas. Entretanto, ao lidar com conceitos de larga difusão, pode ser frutífero algum exercício para situá-los ou algum esforço "para lavar palavra suja", como sugere o poema de Viviane MOSÉ (2006): "Existem outras, e a palavra amor é uma delas, que são muito encardidas e desgastadas pelo uso, o que recomenda esfregar e bater insistentemente na pedra, depois enxaguar em água corrente" (p. 27-28).

Logo, um dos desafios que se coloca aos estudos de gênero é o desgaste das palavras. Com isso, impõe-se a premência da criação de estratégias para desencardi-las, não para encontrar uma suposta pureza original, mas para fugir da mesmice do já sabido, para fazer brotar outras relações. Sobretudo, trata-se de um movimento para trazer à superfície as camadas de discursos que historicamente depositaram-se sobre elas, indicando o quanto têm de criação e construção, ao invés de tomá-las como dadas. Muitos dos artigos consultados trabalham com "palavras sujas", estigmatizadas e caricaturadas (feminismo, feminino, mulher, masculinidade, machismo, gênero), contudo, nem sempre apresentam um investimento no sentido de desnaturalizar os seus significados mais legitimados e disseminados.

Evidentemente, o senso comum está assegurado como uma das formas de regulação das vivências e visões de mundo, o que aponta para a relevância de interrogá-lo. Afirmar que toda mulher possui um talento natural para cuidar do lar e para a criação das crianças, por exemplo, é um discurso que uma grande parcela da população acataria sem qualquer objeção. É, contudo, uma asserção de teor fortemente essencialista, uma vez que estabelece uma essência unívoca e imutável. Advoga, ainda, em favor de uma "natureza feminina/masculina", pois prevê a universalização da experiência de mulheres e homens dentro de limites identificáveis e pré-determinados, apagando as múltiplas formas que podem vir a assumir.

Iniciamos tensionando tais aspectos com o artigo "O machismo em imagens" (Evaldo Miranda de ARAÚJO, 2009), no qual temos um relato de experiência de um projeto realizado durante o estágio supervisionado do curso de Licenciatura em Educação Artística em Mari-PB. O objetivo do trabalho desenvolvido junto a uma turma do Ensino Fundamental durante as aulas de Artes Visuais consistia em buscar "vestígios de machismo" (ARAÚJO, 2009, p. 3291) na arte paraibana, no cinema, na música, nas imagens veiculadas pela mídia e nas próprias atitudes dos/as alunos/ as. A noção de machismo é apresentada como um processo de perda do domínio dos homens sobre as mulheres, em que eles "assistem constrangidamente [a]o poder lhe fugindo às mãos" (ARAÚJO, 2009, p. 3283). Para evitar a "libertação da mulher", eles tentariam impedir esse processo através de "violência psicológica e física contra as mulheres" (ARAÚJO, 2009, p. 3283).

Em uma das atividades realizadas, o autor propõe que os/as alunos/as busquem indícios de comportamentos machistas nas imagens da arte paraibana. Numa arguição sobre as obras dos artistas escolhidos, alguns/algumas alunos/as afirmam não identificar relações com o machismo e outros/as, por sua vez, caracterizam os homens retratados como "seres grosseiros, insensíveis e possivelmente machistas" (ARAÚJO, 2009, p. 3288). Em outra atividade, o autor pergunta aos alunos: "Você se considera machista? Por quê?" (ARAÚJO, 2009, p. 3289). Sem obter respostas às perguntas, aparentemente direcionada aos meninos, as meninas passam a denunciar atitudes machistas, enquanto eles "não quiseram admitir e sempre justificavam suas ações" (ARAÚJO, 2009, p. 3289).

A partir da leitura desse relato, gostaríamos de projetar - o que significa que estamos tentando pensar para além do que está contido nele - algumas possíveis armadilhas desse tipo de abordagem. Ao que parece, a discussão de gênero se estabeleceu a partir de uma polarização mulheres vítimas versus homens perversos, o que pode incitar uma espécie de confronto entre 
sexos. Conforme o relato, as meninas apontam o machismo que consideram ser praticado pelos meninos ou representado nos artefatos visuais disponibilizados pelo professor. Em sua defesa, os meninos parecem ansiosos por justificar o rótulo "machista". Sem uma maior contextualização histórica sobre a discussão de gênero e, até mesmo, sobre a noção de machismo, esse tipo de debate pode se restringir a uma condenação moral em torno de atitudes e imagens machistas, consideradas ruins e inadequadas. Ademais, pode contribuir para fixar estereótipos dualistas de gênero (homens controladores, mulheres submissas etc.), alimentando discursos antagonistas entre os/as alunos/as que anseiam pela legitimação moral diante dos olhos do/a professor/a.

O conceito de machismo, que aparentemente foi o fio condutor das atividades, parte do pressuposto de que um dos polos possui todo o poder e exerce-o de maneira irrestrita e tirânica sobre o outro. Diferentemente da analítica foucaultiana (FOUCAULT, 2014), em que o poder não é necessariamente nefasto e é inseparável da capacidade de resistir, aqui há uma vilanização de quem o detém (os homens) e, consequentemente, a vitimização daquele cuja posse é privada (as mulheres). Essa abordagem pode sugerir a ideia de que a mulher seja totalmente desprovida da capacidade de luta, reação, resistência. Tal noção de machismo permearia também os discursos e práticas dos/as alunos/as, produzindo, no limite, uma espécie de disputa pelo poder, um cabo de guerra que terá apenas um vencedor ao final.

O segundo artigo que problematizamos se intitula "Interculturalidade e gênero no ensino de artes visuais: vivências de uma brasileira em meio a egípcias de Alexandria" (Roberta Melo ARAÚJO, 2014). Nele, a autora defende que a adoção de uma abordagem ancorada na "interculturalidade" possibilite "reconhecer e aceitar" culturas estrangeiras (ARAÚJO, 2014, p. 4) no ensino de Artes Visuais. Com o objetivo de "entender o universo feminino" (ARAÚJO, 2014, p. 2) em contextos sociais diversos, a autora apresenta um conjunto de fotografias, de sua própria autoria, que retrata mulheres egípcias. Dissertando sobre uma possível convivência entre as mulheres brasileiras e egípcias, Araújo prevê que provavelmente "as primeiras tendessem a fazer as segundas a mudar sua atitude quanto a ter direitos e respeito iguais aos que são concedidos aos homens" (ARAÚJO, 2014, p. 9). Já as egípcias empenhar-se-iam em "convencer as brasileiras a cobrir o corpo, a aceitar as vontades do marido e fazer de tudo para ganhar o maior número possível de joias como reconhecimento do esposo pela dedicação delas" (ARAÚJO, 2014, p. 9).

Observa-se aqui uma abordagem que pode ter como implicação a petrificação da identidade da mulher estrangeira, assim como da própria mulher brasileira. Ambas, brasileiras e egípcias, parecem ser tomadas como categorias identitárias encerradas e homogêneas. Subentende-se, pela argumentação da autora, que a mulher brasileira e, por extensão, a mulher ocidental, é plenamente livre, goza dos mesmos direitos políticos que os homens, enquanto às egípcias e às orientais só resta "aceitar as vontades do marido" e ter reconhecimento através das joias adquiridas. Além disso, considerando a vestimenta ou o quanto o corpo pode ser exibido, mede-se o nível de liberdade de uma e de outra, ou seja, quanto mais escondido for o corpo, menor é o espaço de liberdade. Enquanto ambas diferem nesse aspecto - a brasileira cultua o seu corpo e a egípcia esconde-o-, as duas unem-se pelo quesito "sensibilidade" e "culto à beleza" (ARAúJO, 2014 , p. 8). Vê-se, desse modo, o tipo de proposta que pode se limitar à celebração de uma alegada natureza feminina, encontrando paralelos nos discursos do senso comum.

Passamos ao terceiro e último artigo discutido nessa seção, "Poética visual do feminino na educação: a identidade feminina adolescente" (Daysa Darcin ALSOUZA e Roberta PUCCETTI, 2011). O texto narra atividades realizadas durante uma oficina com um grupo de alunas de uma escola pública, tendo como objetivo "desenvolver a produção poética das alunas a partir de questões relativas ao universo feminino" (ALSOUZA; PUCETTI, 2011, p. 392). Vinculando-se a teorias psicanalíticas, as autoras propõem atividades - $\mathrm{O}$ "desenho por meio de estímulos com manchas" (ALSOUZA; PUCETTI, 2011 , p. 397) é uma delas - visando à abordagem do inconsciente.

Buscando desvelar uma essência feminina, o estudo concentra-se nos aspectos corporais da mulher e em seus possíveis significados "inconscientes". Na análise dos desenhos criados pelas alunas, alega-se, por exemplo, que mulheres de cabelo solto são "flexíveis e inovadoras" e que as que o prendem são "conservadoras" (ALSOUZA; PUCCETTI, 2011, p. 401); representações que, certamente, não destoam do imaginário do senso comum e possuem força subjetivadora. As criações das alunas são tratadas, ainda, como uma espécie de confissão sobre a "identidade feminina adolescente", em que se admite uma relação direta entre a imagem e a sua criadora. A potencialidade da arte de ficcionar e transgredir é suplantada pela busca de uma verdade interior do sujeito, que tem um fragmento da sua existência capturado e cristalizado na criação de uma imagem.

Um aspecto a destacar nestes estudos é a aproximação, por vezes, tópica, à discussão de gênero. Especialmente em Araújo (2014) e Alsouza e Puccetti (2011), existe um entendimento de que, ao envolver mulheres como "sujeitos 'empíricos' (Fúlvia ROSEMBERG, 2001, p. 59) da pesquisa (o primeiro caso quando retratadas em fotografias e o segundo como alunas das oficinas), automaticamente a discussão de gênero é acionada. No corpo do texto há poucas referências a 
conceitos e autores/as que reportem à discussão de gênero. Verifica-se, nessas pesquisas, uma acepção de gênero que poderíamos afirmar ser a tônica de uma parcela significativa dos artigos consultados nos dois eventos. Trata-se, contudo, de uma acepção restrita, na qual as inúmeras correntes teóricas que discutem gênero não são levadas em consideração, tampouco compõem um horizonte teórico das argumentações desenvolvidas. Rosemberg (2001), Silvia Regina Marques JARDIM e Anete ABRAMOWICZ (2005), em dois levantamentos de grande escala sobre o estado da categoria gênero nas pesquisas em educação no Brasil, também observam uma correspondência frequente entre 'mulher' e 'gênero', sendo que esses termos "têm sido utilizados como sinônimos" (JARDIM; ABRAMOWICZ, 2005, p. 106).

Já tentando compreender a razão pela qual os/as autores/as optam por não utilizar gênero efetivamente como categoria de análise, Jardim e Abramowicz (2005) nos fornecem uma possível explicação. Elas alegam que é comum que os/as autores/as percebam que as relações de gênero perpassam suas pesquisas quando estas já estão em andamento, ou seja, a perspectiva de gênero não é assumida desde o início. Supõe-se, dessa forma, que os/as autores/as se empenhariam na incorporação de um novo aparato teórico/metodológico ainda durante a pesquisa. Essa ponderação deve ser considerada também no caso dos artigos que citamos, pois, como vimos, alguns destes são relatos de experiência de estágios curriculares ou de contatos iniciais com a docência. São, portanto, realizados por pesquisadores/as que estão se aproximando da educação escolar, do processo de pesquisa e, possivelmente, da discussão de gênero. Entretanto, concordamos com as autoras quando advertem que a ausência de articulação com os estudos de gênero pode "provocar um empobrecimento do trabalho, pois essa categoria é, muitas vezes, questionadora de universalizações, já que intervém no pensamento binário e leva consigo as forças da multiplicidade" (JARDIM; ABRAMOWICZ, 2005, p. 111).

Nota-se, nas pesquisas destacadas anteriormente, o quanto o uso tênue do conceito gênero pode conduzir a argumentações pautadas em universalizações, polarizações e abordagens unidimensionais. De modo geral, são artigos que buscam enfrentar discriminações, variadas formas de violência contra a mulher, exclusões de diferentes etnias, mas que, por fornecerem pouco instrumental teórico para pensar as relações de gênero, acabam por conservar e reforçar certas identidades femininas e masculinas já estratificadas no senso comum. Além disso, podem assumir um tom de aconselhamento, no qual a potência política da discussão de gênero é ofuscada por uma lógica enraizada na moral, reduzindo-se a uma advertência sobre o certo e o errado. Sem uma maior problematização sobre os modos de captura das subjetividades e os processos históricos, culturais e políticos em jogo nesse processo, podem limitar-se à condenação ou à absolvição dos sujeitos envolvidos na experiência pedagógica.

A dificuldade de superar o senso comum, os essencialismos e as polarizações, entretanto, pode ser sintomática da pauperização do debate sobre gênero nas instâncias de formação docente em Artes Visuais. Isto posto, ressaltamos que lançar mão desses usos não implica um demérito ou desqualificação das pesquisas, mas é, fundamentalmente, fruto de um conjunto de possibilidades que configuram o contexto em que se inserem. Ao apontar prováveis armadilhas, portanto, nossa tarefa esteve longe de condenar determinados usos teóricos, mas, inversamente, no sentido de contribuir para algum avanço da discussão, buscamos pensar nos funcionamentos e nos possíveis efeitos desses usos. Em vista da escassez de literatura que se debruça sobre essa problemática, há que se considerar, ainda, que tais pesquisas injetam uma contribuição inestimável e, sem dúvida, são referências a serem consultadas por muitos/as professores/as e pesquisadores/as.

\section{O feminismo em anexo}

Agregar sujeitos considerados ausentes e marginalizados, bem como adicionar temas a uma concepção canônica de Arte pode, num primeiro momento, reparar uma urgência histórica e política, mas se revelar insuficiente na medida em que conserva as principais premissas do pensamento hegemônico, as mesmas que outrora serviram para justificar exclusões. Nesse tipo de abordagem, tanto há a indulgência com a dimensão arbitrária do cânone, quanto a sua suavização e ajuste, pois, agora, ele precisa acolher o que ele mesmo havia negado. Por vezes, o debate que versa sobre as relações de gênero nas Artes Visuais não é suprimido, porém amansado, harmonizado e colocado no lugar em que permite que tudo se acomode, o anexo. Para exemplificar esse tipo de abordagem, trazemos como amostra o artigo "Mulheres artistas: relato de uma aprendizagem mútua" (Silvia Tereza Moura SILVA; Fabiana Souto Lima VIDAL, 2014), que consiste em um relato de uma experiência pedagógica, vinculada ao PIBID (Programa Institucional de Bolsa de Iniciação à Docência), e que foi desenvolvida em uma escola pública.

Ponderamos, novamente, quanto às condições que dão suporte ao estudo: um relato de contatos iniciais com a docência em Arte ainda durante o processo formativo. É um estudo que se caracteriza por enveredar em uma problemática temida por muitos/as professores/as, o que, sem dúvida, dá sinais de uma postura política atenta às relações de poder que permeiam as formas de narrar a arte no currículo. A proposta revela um escopo vultoso e de grande relevância face à 
precariedade dessa discussão no espaço escolar. No sentido de problematizar possíveis efeitos, todavia, apontamos como alguns encaminhamentos dessa abordagem podem conduzir a uma estratégia reformista.

Partindo da constatação do lugar secundário ocupado pelas mulheres artistas no currículo do ensino de Artes Visuais, as autoras propõem, como foco temático para o ano letivo do $1^{\circ}$ ano do Ensino Médio, o estudo de artistas mulheres ao longo da história da arte. Objetivando "trabalhar na contramão do silenciamento" (SILVA; VIDAL, 2014, p. 4), desenvolvem, então, uma série de atividades voltadas para o estudo das artistas organizadas de acordo com a abordagem triangular, " contemplando práticas de "leitura de imagem, contextualização e produção" (SILVA; VIDAL, 2014, p. 4). Os dois primeiros eixos, leitura de imagem e contextualização, envolveram um intenso movimento de pesquisa protagonizado pelos/as alunos/as mediante um mapeamento de artistas mulheres de diferentes períodos da história da arte, dispostas cronologicamente em uma linha do tempo. Na culminância do projeto, e cumprindo o eixo produção artística, propôs-se aos/ às alunos/as "realizar uma síntese visual", na qual "teriam que contemplar com desenhos elementos, traços, estilos, detalhes, temáticas exploradas pelas artistas" (SILVA; VIDAL, 2014, p. 10).

Ainda que a atenção dirigida aos processos de exclusão e às relações de poder tenha tido um espaço importante como elemento introdutório do projeto, não parece ter permitido interrogar o olhar estratificado da história da arte hegemônica, mas, ao invés disso, figurou apenas como um preâmbulo ou um anexo isolado do todo. Tal aspecto é sugerido pelo modo como as obras das artistas são contempladas, cuja primazia dada aos aspectos formais, estilísticos, cronológicos, biográficos, remonta aos registros historiográficos mais tradicionais.

A partir do diagnóstico da ausência de artistas mulheres no ensino de Artes Visuais, muitas propostas podem assumir uma tática reparatória propondo um estudo exclusivo de artistas mulheres ao longo da história. Acolhendo as ideias de historiadoras da arte como Griselda POLLOCK (2003), acreditamos que esse resgate se faz mister e instala a necessidade de nos mantermos em constante vigilância para consolidá-lo. Em contrapartida, a adição de mulheres a um currículo no qual o alicerce metodológico mantém-se inalterado pode reter o debate na superfície. Em outras palavras, acrescenta-se um grande conjunto de artistas mulheres a dois paradigmas que permanecem inabaláveis e tendem a destacar a figura do artista gênio: a história hegemônica das Artes Visuais e a abordagem triangular. ${ }^{12}$

A obediência a esses parâmetros de análise das obras de arte pode tanto atender à reiteração de um modo de operar com as Artes Visuais consolidado nas instâncias de formação docente, quanto tornar a dimensão política da discussão de gênero mais palatável, mais branda e menos problemática. Talvez esta seja uma resposta mais imediata e mais possível levando em consideração a conjuntura que envolve a formação docente, o atual contexto político e a ausência de repertório em relação ao tema. É uma resposta que conjuga os saberes acumulados durante o percurso formativo (a abordagem triangular e a abordagem da história da arte) com novas demandas políticas, de modo que esses dois domínios não se anulem.

\section{Esboçando intervenções feministas}

Após todas as movimentações e tensionamentos empreendidos até aqui, gostaríamos de esboçar não atividades, roteiros e receitas a serem desenvolvidas em sala de aula, mas algumas abordagens e posturas que podem ser assumidas. E a adoção do verbo esboçar, aqui, não é gratuita. Esboços porque proposições que não se pretendem assertivas ou definitivas. Esboços porque ensaios, construções inacabadas. Convém destacar que tais esboços se contaminam, de alguma forma, com as intervenções feministas na história da arte pretendidas por Pollock (2003). Uma das provocações da autora, no que tange às práticas feministas na história da arte, consistia em questionar se "acrescentar mulheres à história da arte é o mesmo que produzir história da arte feminista?" (POLLOCK, 2003, p. 1). Deslocando essa provocação para o contexto do ensino de Artes Visuais em escolas, poderíamos indagar: seria suficiente acrescentar artistas mulheres no currículo da disciplina? Na esteira das discussões de Pollock, o que propomos é a possibilidade de um debate de gênero que não se restrinja a uma política de cotas, mas que assuma a forma de um profundo e permanente questionamento em torno "dos objetos que nós estudamos, e das teorias e métodos com os quais nós fazemos isto" (POLLOCK, 2003, p. XXVII [tradução nossa]).

\footnotetext{
11 A Proposta ou Abordagem Triangular, formulada por Barbosa (1998), tem sido uma das perspectivas metodológicas mais difundidas nas instâncias de formação docente, sendo extensivamente empregada no ensino de Artes Visuais no Brasil. A proposta baseia-se em três eixos: o fazer artístico, as leituras das obras de arte e a contextualização delas (BARBOSA, Ana Mae. Tópicos Utópicos. Belo Horizonte: C/Arte, 1998).

12 É sabido que uma das práticas mais recorrentes da abordagem triangular, à revelia das intenções da sua criadora, tem sido a exaltação dos grandes artistas da história da arte, majoritariamente homens, brancos europeus ou estadunidenses. No processo de contextualização desses artistas, é comum a redução aos dados biográficos, que, muitas vezes, narram a genialidade destes. E, ainda, no eixo leitura de imagem, recorre-se frequentemente a uma análise formalista, destacando os elementos da linguagem visual e o estilo do artista.
} 
Um primeiro ponto de inflexão que traçamos, portanto, abarca precisamente a problemática da elisão das mulheres artistas nas inúmeras esferas da área de arte e educação. Como vimos, coadunam-se vários indícios acerca do desconhecimento dos/as docentes sobre as artistas, além da ausência delas nos livros e materiais didáticos, nas publicações acadêmicas da área e no currículo escolar. Portanto, essa permanece como uma questão urgente. Resta-nos indagar: como tornar as mulheres artistas visíveis?

Sem dúvida, uma rota que se anuncia é a realização de projetos em torno do tema "mulher artista". É uma rota que pode potencializar discussões e práticas fecundas. Todavia, há que se ter em conta os impasses e riscos advindos dela. Evidentemente, isso não significa que tal possibilidade deva ser abandonada. Ao contrário. Um projeto pedagógico sobre o tema pode ser o mote para problematizar a multiplicidade de femininos, para desnaturalizar estereótipos e representações usuais. É necessário, contudo, ter atenção às narrativas criadas em torno dessas artistas e manter os sentidos afiados ao que pode estar interdito e invisibilizado pela própria narrativa que criamos, à revelia de nossas intenções.

Mesmo em projetos que englobem apenas as artistas mulheres, é possível, por exemplo, que haja a permanência de uma história da arte canônica, privilegiando, por conseguinte, um feminino hegemônico: mulheres brancas, ocidentais, europeias, estadunidenses, heterossexuais, cristãs. Pode-se também resguardar o bojo de análise formalista alijado das questões políticas e de gênero. Ou, ainda, apresentar uma disposição linear e evolucionista das artistas na história, mediante uma narrativa una e coesa, que torna pálidas ou inexistentes as descontinuidades, as tensões e as pluralidades de suas obras.

Uma postura que não fortaleça um feminino hegemônico e essencializado pode emergir do questionamento da categoria "mulher" que estamos colocando em jogo em nossas práticas. Como sugere Pollock (2003, p. 12-13), embora "uma das responsabilidades primárias de uma intervenção feminista dev[a] ser o estudo das mulheres como produtoras", deve-se recusar a "suposição de uma essência dada da mulher fora ou parcialmente imune às condições sociais". Nesse sentido, ter no horizonte a diversidade de experiências e práticas das artistas nos distintos contextos e épocas pode contrapor-se às narrativas unidimensionais. Para tanto, estabelecer tramas diversas com marcadores raciais, religiosos, regionais, nacionais, étnicos, de idade e de sexualidade pode potencializar a pletora de subjetividades sob o guarda-chuva da expressão "mulher artista". Com esses cruzamentos, cria-se uma abertura para problematizar a miríade de poéticas de enfrentamento que as artistas levam a cabo em seus trabalhos, além de trazer à tona uma multidão heterogênea de representações femininas.

Não obstante, para além de projetos que incluam exclusivamente as artistas mulheres, pensamos que se deva fazer o esforço para que elas possam estar presentes nas demais abordagens artísticas, assim como nas abordagens da história da arte desenvolvidas pelo/a professor/a. Essa estratégia requer uma atenção permanente às nossas escolhas, àquilo que produzimos com 0 que apresentamos aos/às alunos/as e àquilo que produzimos mediante o que deixamos de apresentar. É uma postura de reconhecimento de que nossas práticas docentes também são parte das relações de poder e que, com elas, se pode produzir muitas coisas, inclusive, discursos sexistas, racistas e antidemocráticos (LOURO, 2003).

A presença constante de mulheres artistas nas escolhas docentes pode permitir desfazer a sensação de uma história paralela ou de uma história em anexo, à parte da 'grande história da arte masculina' que pode continuar coexistindo mesmo que haja uma discussão feminista. É precisamente nessa 'grande história da arte' que se quer intervir, colocando-a em suspenso, ao invés de produzir uma réplica da 'grande história' na versão feminina.

Alinhavando um pouco mais esse esboço feminista, é imprescindível contemplar as inúmeras problemáticas que despontam no dia a dia em sala de aula, uma vez que, na espreita e com o olhar aberto para identificar os atravessamentos de gênero nas demandas cotidianas, pode-se criar itinerários diversos. Discursos do senso comum, por exemplo, seguramente fazem parte das concepções de gênero, sexualidade, masculinidade, feminilidade e feminismo que circulam no cotidiano escolar. O que fazer com isso? Recusá-los ou sentenciá-los como errados? Pensamos que uma outra via possível é tomar o senso comum como um ponto de partida ou um foco de problematização. Esta é uma tarefa de ordem política de grande relevância, visto que concepções do senso comum continuam a dar suporte à permanência das desigualdades e das discriminações. Uma estratégia que pode permitir suspeitar das verdades difundidas no senso comum é a sua historicização, trazendo à baila os discursos religiosos, políticos, científicos, culturais que as nutrem nas diferentes sociedades.

Um outro ponto a ser considerado é a dificuldade de encontrar um tom de fala e de aproximação que não esteja amparado num pensamento moralista. Constranger e acusar atitudes "machistas" pode ter algum efeito imediato, entretanto, pode acentuar uma rivalidade entre elas e eles, que, no limite, acaba por barrar a possibilidade de um diálogo aprofundado. Talvez, afastar-se de uma atitude de julgamento e assumir uma postura comprometida com a problematização possa ganhar uma repercussão menos polarizada junto aos/às alunos/as. Isso implica, dentre outras coisas, 
evidenciar que aquilo que as pessoas fazem e pensam, antes de ser uma questão tão somente de caráter individual, diz respeito às condições de possibilidade de um dado contexto, aos discursos e às representações de uma época, às relações de poder e saber em que estão mergulhadas.

Após esboçar possibilidades, além de recuperar os [desa]fios que emaranham o cruzamento gênero e ensino de Artes Visuais, salientamos a importância de um posicionamento intelectual modesto, que recusa a pretensão universal e está comprometido com a dimensão social mais imediata (LOURO, 2003). Não são das resistências e dos horizontes quiméricos de que tratamos, portanto. Noutra direção, trata-se daquelas resistências possíveis, concretas, ínfimas. Trata-se dos horizontes que nos cercam diariamente, do chão em que assentamos nossas práticas. $\mathrm{E}$, justamente por nos reconhecermos dentro das relações de poder, criamos "formas de intervir mais viáveis e próximas" (LOURO, 2003, p. 124). Assim, atentos à problemática de gênero, e a toda complexidade que dela advém, quiçá, possamos desenhar e confabular outros horizontes e políticas de atuação docente em Artes Visuais.

\section{Referências}

ALSOUZA, Daysa Darcin; PUCCETTI, Roberta. "Poética visual do feminino na educação: a identidade feminina adolescente". In: ENCONTRO DA ASSOCIAÇÃO NACIONAL DE PESQUISADORES EM ARTES PLÁSTICAS - SUBJETIVIDADES, UTOPIAS E FABULAÇÕES, 20., 2011 , Rio de Janeiro, UERJ. Anais... Rio de Janeiro: ANPAP, 2011 , p. 392-405.

ARAÚJO, Evaldo Miranda de. "O machismo em imagens". In: ENCONTRO DA ASSOCIAÇÃO NACIONAL DE PESQUISADORES EM ARTES PLÁSTICAS - TRANSVERSALIDADES NAS ARTES VISUAIS, 18., 2009, Salvador, UFBA. Anais... Salvador: ANPAP, EDUFBA, 2009, p. 3281-3295.

ARAÚJO, Roberta Melo. "Interculturalidade e gênero no ensino de artes visuais: vivências de uma brasileira em meio a egípcias de Alexandria". In: CONGRESSO NACIONAL DA FEDERAÇÃO DOS ARTE/ EDUCADORES DO BRASIL - ARTE/EDUCAÇÃO CONTEMPORÂNEA: METAMORFOSES E NARRATIVAS DO ENSINAR E APRENDER, 24., 2014, Ponta Grossa. Anais... Ponta Grossa: UEPG, 2014.

BRASIL. Lei 13.415, de 17 de fevereiro de 2017. Disponível em https://legis.senado.leg.br/norma/ 602639.

BRASIL. Lei 9.394, de 20 de dezembro de 1996. Disponível em http://www.planalto.gov.br/ccivil_03/ leis/19394.htm.

BUCHMANN, Luciano Parreira; FIGUEIREDO, Mariana Galli. "Professoras e suas escolhas: estratégias à dominação masculina no ensino da arte por meio do grupo de estudos em artes visuais - Polo Arte na escola da FAP". In: CONGRESSO NACIONAL DA FEDERAÇÃO DOS ARTE/EDUCADORES DO BRASIL - ARTE/EDUCAÇÃO CONTEMPORÂNEA: METAMORFOSES E NARRATIVAS DO ENSINAR E APRENDER, 24., 2014, Ponta Grossa. Anais... Ponta Grossa: UEPG, 2014.

BUTLER, Judith. Problemas de Gênero: Feminismo e subversão da identidade. Rio de Janeiro: Civilização Brasileira, 2016.

COUTINHO, Andréa Senra. Poéticas do feminino/feminismo na arte contemporânea: transgressões para o ensino de artes visuais em escolas. 2009. Tese (Doutorado em Estudos da Criança) Universidade do Minho, Braga, Portugal.

DIAS, Belidson. O i/mundo da educação da cultura visual. Brasília: Editora da Pós-Graduação em Arte da Universidade de Brasília, 2011.

DIAS, Taís Ritter. Ensino de arte e feminismos: urdiduras entre relações de poder e resistências. 2017. Dissertação (Mestrado em Educação) - Universidade Federal do Rio Grande do Sul, Porto Alegre, RS, Brasil.

DREYFUS, Hubert; RABINOW, Paul. Michel Foucault, uma trajetória filosófica. Rio de Janeiro: Forense Universitária, 1995.

EFLAND, Arthur; FREEDMAN, Kerry; STUHR, Patrícia. La educación en el arte posmoderna. Barcelona: Paidos, 2003.

ERIBON, Didier. Michel Foucault. São Paulo: Companhia das Letras, 1990.

FOUCAULT, Michel. A história da Sexualidade I: A Vontade de Saber. Rio de Janeiro/São Paulo: Paz \& Terra, 2014. 
FRADE, Isabela; CAETANO, Alessandra; GÓES, Jéssica; SARAIVA, Letícia. "Refletores em convergência: questões de gênero". In: CONGRESSO NACIONAL DA FEDERAÇÃO DOS ARTE/EDUCADORES DO BRASIL - ARTE/EDUCAÇÃO: CORPOS EM TRÂNSITO, 22., 2012, São Paulo. Anais... São Paulo: UNESP, 2012.

JARDIM, Silvia Regina Marques; ABRAMOWICZ, Anete. "Tendências da produção paulista sobre gênero e educação: um balanço de dissertações de mestrado". Revista Brasileira de PósGraduação, v. 2, n. 3, p. 93-117, mar. 2005.

LOPONTE, Luciana Gruppelli. "Pedagogias visuais do feminino: arte, imagens e docência". Currículo sem fronteiras, v. 8, n. 2, p. 148-164, jul./dez. 2008.

LOPONTE, Luciana Gruppelli. "Artes visuais, feminismos e educação no Brasil: a invisibilidade de um discurso". Universitas Humanística, p. 143-163, jan./jun. 2015.

LOURO, Guacira Lopes. Gênero, sexualidade e educação: uma perspectiva pósestruturalista. Petrópolis: Vozes, 2003.

MOSÉ, Viviane. Toda Palavra. Rio de Janeiro/São Paulo: Record, 2006.

PINTO, Céli Regina Jardim. Com a palavra o senhor presidente José Sarney: ou como entender os meandros da linguagem do poder. São Paulo: Hucitec, 1989.

POLLOCK, Griselda. Vision and difference: feminism, feminity and the histories of art. New York: Routledge, 2003.

PRECIADO, Beatriz. "Multidões queer: notas para uma política dos 'anormais'”. Revista Estudos Feministas, Florianópolis, v. 19, n. 1, p. 11-20, jan./abr. 2011.

ROSEMBERG, Fúlvia. "Caminhos cruzados: educação e gênero na produção acadêmica". Educação e Pesquisa, São Paulo, v. 27, n. 1, p. 47-68, jan./jul. 2001.

SCHWENGBER, Maria Simone Vione. "O uso das imagens como recurso metodológico". In: MEYER, Dagmar Estermann; PARAísO, Marlucy Alves (Orgs.). Metodologias de pesquisas pós-críticas em educação. Belo Horizonte: Mazza Edições, 2012. p. 261-278.

SCOTT, Joan. "Gênero: uma categoria útil de análise histórica". Educação e Realidade, v. 20, n. 2, p. 71-99, jan./dez. 1995.

SILVA, Silvia Tereza Moura; VIDAL, Fabiana Souto Lima. "Mulheres artistas: relato de uma aprendizagem mútua". In: CONGRESSO NACIONAL DA FEDERAÇÃO DOS ARTE/EDUCADORES DO BRASIL - ARTE/ EDUCAÇÃO CONTEMPORÂNEA: METAMORFOSES E NARRATIVAS DO ENSINAR E APRENDER, 24., 2014, Ponta Grossa. Anais... Ponta Grossa: UEPG, 2014.

SOUZA, Edvandro Luise Sombrio de. Fronteiras, lugares de solidariedade: O que dizem os programas de Artes Visuais para os Anos Iniciais do Ensino Fundamental sobre as diversidades sexuais e de gênero? 2017. Dissertação (Mestrado em Educação) - Programa de Pós-Graduação em Educação, Universidade Federal do Rio de Janeiro, Rio de Janeiro, RJ, Brasil.

Taís Ritter Dias (taisritter@gmail.com) é licenciada em Artes Visuais (UFRGS) e mestra em Educação (UFRGS). Professora de Arte na rede pública estadual, no município de Santo Antônio da Patrulha, Rio Grande do Sul. É integrante do grupo de pesquisa ARTEVERSA - Grupo de estudo e pesquisa em arte e docência (www.ufrgs.br/arteversa).

Luciana Gruppelli Loponte (luciana.loponte@ufrgs.br) é doutora e mestre em Educação, licenciada em Educação Artística - Habilitação Artes Plásticas. Professora da Faculdade de Educação da Universidade Federal do Rio Grande do Sul, atuando na Graduação e no Programa de Pós-Graduação em Educação. É líder do grupo de pesquisa ARTEVERSA - Grupo de estudo e pesquisa em arte e docência (www.ufrgs.br/arteversa). 


\section{COMO CITAR ESSE ARTIGO DE ACORDO COM AS NORMAS DA REVISTA}

DIAS, Taís Ritter; LOPONTE, Luciana Gruppelli. "Gênero e ensino de Artes Visuais: desafios, armadilhas e resistências". Revista Estudos Feministas, Florianópolis, v. 27, n. 3, e56280, 2019.

\section{CONTRIBUIÇÃO DE AUTORIA}

Taís Ritter Dias - Concepção, coleta de dados e análise de dados, elaboração do manuscrito, redação, discussão de resultados.

Luciana Gruppelli Loponte - Redação, discussão dos resultados.

\section{FINANCIAMENTO}

O presente trabalho foi realizado com apoio da Coordenação de Aperfeiçoamento de Pessoal de Nível Superior - Brasil (CAPES) - Código de Financiamento 001

\section{CONSENTIMENTO DE USO DE IMAGEM}

Não se aplica

APROVAÇÃO DE COMITÊ DE ÉTICA EM PESQUISA

Não se aplica

\section{CONFLITO DE INTERESSES}

Não se aplica

\section{LICENÇA DE USO}

Este artigo está licenciado sob a Licença Creative Commons CC-BY International. Com essa licença você pode compartilhar, adaptar, criar para qualquer fim, desde que atribua a autoria da obra.

\section{HISTÓRICO}

Recebido em 09/04/2018

Reapresentado em 09/10/2018

Aprovado em 18/10/2018

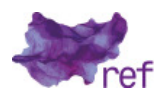

